\title{
American MNEs: In Search of Legitimacy When You're WEIRD
}

\author{
Craig V. VanSandt \\ University of Northern Iowa
}

\author{
Matthew C. Mitchell \\ Drake University
}

\author{
Mukesh Sud \\ Indian Institute of Management Ahmedabad
}

\begin{abstract}
Presuming that American Multinational Enterprises (AMNEs) prefer to be viewed as legitimate, socially responsible firms in their host countries, we seek to provide answers to the question of how they can best determine ethical standards when faced with multiple, frequently conflicting operating environments? After exploring many of the reasons why identifying and understanding hosts' moral matrices is extremely confounding, the authors review prior and existing efforts to bridge them and suggest specific steps that AMNEs can employ to better accommodate their ethics to the vastly different cultures in which they operate.
\end{abstract}

Keywords: Legitimacy, Moral Matrices, Multinationals, WEIRD

\section{INTRODUCTION}

Why do American (specifically US-based) multinational enterprises (AMNEs) ${ }^{1}$ regularly have difficulty understanding local cultural and moral standards, thereby offending local sensibilities and damaging their legitimacy to conduct business operations in host countries? We contend that AMNEs face greater difficulties establishing institutional legitimacy than do their counterparts from other nations. For reasons we will explicate in this paper, AMNEs may understand less about the local cultures and ethics of host countries than do other MNEs. Studies of disparate societies show that Western, educated, industrialized, rich, democratic (WEIRD) people are, in many ways, significantly different than the rest of the human species. Domains in which differences manifest range from visual perception to spatial reasoning to self-concepts to, most pertinent to the current research project, moral reasoning. Americans are even more exceptional - in the sense of "different" rather than "better"-when compared to the unusual populations of Westerners. Americans are essentially outliers among outliers (Henrich, Heine, and Norenzayan 2010). As a result of this WEIRDness, AMNEs are more likely to have difficulty establishing corporate legitimacy in culturally distant host cultures and even more likely to have greater complications creating normative legitimacy. ${ }^{2}$ 


\section{Institutional Theory and Legitimacy}

Institutional theory argues that organizations are shaped by their environments through a process of isomorphism (Meyer and Rowan 1977; Powell and DiMaggio 1991) and that their legitimacy is dependent upon acceptance by their surrounding environments (Dowling and Pfeffer, 1975). Legitimacy is based on the fact that the very existence of certain types of organizations depends upon the consent of the society in which they operate. This acquiescence is based on the perception that a certain type of organization serves some useful purpose. Although MNEs are generally viewed from an economic perspective, scholars have recently begun to recognize the importance of cultural and ethical sensitivity to their legitimacy (Kotabe, 2002; Phillips et al., 2000; Suddaby and Greenwood, 2005; Vaara and Tienari, 2008; Vaara, Tienari, and Laurila, 2006). AMNEs can, by becoming more ethically sensitive to their host countries' moral discourses, enhance their normative legitimacy and consequently their acceptance in the local marketplace.

Corporate legitimacy rests on three institutional pillars - regulatory, cognitive, and normative (Scott, 2013). Organizational legitimacy, in the context of this argument, is a "generalized perception or assumption that the actions of an entity are desirable, proper, or appropriate within some socially constructed system of norms, values, beliefs, and definitions" (Suchman, 1995: 574). In the institutional perspective, legitimacy is critical for organizations to be accepted within their environment, in order gain access to necessary resources, to build political, social and cultural capital, and to ensure organizational survival (Dowling and Pfeffer, 1975; Hannan and Freeman, 1977; Kostova and Zaheer, 1999; Meyer and Rowan, 1977; Oliver, 1991).

Our primary focus in this research project will be on the normative pillar. "Moral [or normative] legitimacy reflects a positive normative evaluation of the organization and its activities (e.g. Aldrich \& Fiol, 1994; Parsons, 1960). Unlike pragmatic legitimacy, moral legitimacy is 'sociotropic'-it rests not on judgments about whether a given activity benefits the evaluator, but rather on judgments about whether the activity is 'the right thing to do.' These judgments, in turn, usually reflect beliefs about whether the activity effectively promotes societal welfare, as defined by the audience's socially constructed value system" (Suchman, 1995: 579). In the normative dimension of legitimacy (are the actions of an entity socially desirable or appropriate?), culture is the context for ethics (Stajkovic and Luthans, 1997).

\section{Do MNEs Have Positive Duties to Improve Society?}

In our examination, we will utilize general concepts from business ethics and religion. "Business ethics concerns the study of ethics for and the practice of ethics by profit-oriented enterprises and managers engaged in market activities of buying and selling goods and services" (Windsor, 2004: 734). It involves two different problems - first, whether businesses or their managers should or must follow some type of ethical construct, or whether they can be purely instrumental in their actions. We take the answer to this question as a given, that businesses and their managers do have a positive duty to act ethically rather than instrumentally. ${ }^{3}$ Even one of the foremost proponents of the instrumental approach to profit maximization acknowledged there are limits to such a proposition. "There is one and only one social responsibility of business--to use its resources and engage in activities designed to increase its profits $s o$ long as it stays within the rules of the game, which is to say, engages in open and free competition without deception or fraud" (Friedman 1970: 124; emphasis added). Of course, Friedman's definition of "the rules of the game," limited solely to "open and free competition without deception or fraud," is markedly different than our conception of those rules. This debate about the elements constituting "the rules of the game" is essentially equivalent to Windsor's first question.

All MNEs seek economic success in their host countries and, we argue, should also seek to improve the societies in which they operate. However, if MNEs remain outsiders, "alien to both the cultures and the ecosystems within which they do business - it will be difficult for them to realize their full commercial, let alone social, potential....Clearly then, the next challenge for large corporations will be learning how to become 'indigenous' to the places in which they operate" (Hart, 2010: 38-39). This research project is aimed at helping firms understand host cultures sufficiently to approach indigenous status. 
A related question has vexed scholars for many years - what duties, if any, do business organizations have to improve the societies in which they operate? Many scholars argue that corporations have a negative duty to do no harm, but cannot have a positive duty to do anything outside the economic realm aimed at profit-generating activities (Friedman, 1970). Hsieh (2009) has contributed to the international business ethics literature by arguing that MNEs have a positive duty to help build minimally just institutions when operating in societies that do not already have them. Relying largely on Rawls's (1999) "duty of assistance," in which he argues that members of well-ordered societies have a positive duty to assist burdened societies establish the institutions that will help them become well-ordered, Hsieh (2009) extends that call specifically to MNEs. He acknowledges that many scholars object to such a positive duty on two bases: that positive duties to help develop minimally just institutions do not apply to MNEs, and that such efforts are beyond the scope of their legitimate activities.

However, Hsieh (2009) grounds his argument for the positive duty of helping develop minimally just institutions in the negative duty to do no harm. He notes that MNEs' business activities often generate negative externalities that harm local citizens. Part of the responsibility of just institutions is to protect their citizens from these types of harms. It is morally wrong for MNEs to profit from market failures that allow unrecompensed externalities, thus justifying MNEs' participation in building just institutions. We concur with Hsieh's arguments, but add a more basic justification for MNEs' positive duties in this area. Hsieh and other scholars often treat corporations' rights and duties as if they are equivalent to humans' unalienable rights. We contest this notion, noting that corporations are mere legal fictions, and thus have only the rights and duties granted to them under the laws established by a society and its government. ${ }^{4}$ If a particular society wants MNEs to participate in building minimally just institutions, then corporations will have that positive duty, regardless of scholarly views.

Windsor's second question about business ethics is even more pertinent to our inquiry, involving the theoretical and practical aspects of significant variations in ethical standards across borders (Windsor, 2004). Specifically, we will focus on issues related to AMNEs' ability to recognize and fully understand host countries' local culture, moral matrices, and attached meaning systems, and AMNEs' moral hegemony (Wallerstein, 1974, 2004). In their groundbreaking work on Integrative Social Contracts Theory (ISCT), researchers noted the necessity for MNEs to recognize and understand host countries' moral norms. "In order to render normative judgments under the contractarian framework presented, it is necessary first to make accurate empirical findings concerning the ethical attitudes and behaviors of members of relevant communities" (Donaldson and Dunfee, 1994: 254; emphasis added).

Utilizing institutional theory, we will employ the lenses of WEIRDness (Henrich et al., 2010), the need for semantic fit and recontextualization (Brannen, 2004), and the Big Three of Morality (Shweder et al., 1997), to examine why AMNEs have difficulty understanding local moral norms and effectively adapting to them. These three lenses correspond closely to three levels of analysis - the individual, firm, and cultural tiers.

We also utilize the construct of religion to provide a richer description of the local normative institutional context. Specifically, we will examine the ability of the religious establishment to influence the general perception that corporate action in the local environment is or is not desirable or proper. It is clear that the religious establishment of a locality has a unique and influential voice that speaks with authority regarding the socially constructed system of norms, values, beliefs and definitions. Religion differentiates the local normative institutional context with a unique and co-created blend of national and religious narratives (Kinnvall, 2004; Micklethwait and Wooldridge, 2009; Tracey, 2012).

Thus, the research question with which we will engage is: How can AMNEs most effectively develop and maintain normative legitimacy in multiple host countries given the heterogeneity of local institutional contexts?

This paper will make contributions to institutional theory by identifying factors that make Americanbased MNEs and managers WEIRD and that may hinder their ability to become an integral part of host countries' markets and cultures. We will first identify issues peculiar to American society that contribute to AMNEs' particular difficulty in recognizing, understanding, and adapting to host cultures. We will then examine current and historic attempts to alleviate the problem of operating with significant variations 
in ethical standards across borders. Finally, we will suggest alternative approaches that will assist AMNEs in their quest for legitimacy in host countries.

\section{AMNES - SKEWED WEIRD}

In this section we propose that AMNEs and their managers are characterized by insularity and a sense of self-superiority that leads to overconfidence in ethical decisions. To support these assertions we argue that natives of WEIRD countries are even weirder than we once thought — and the US even more so. We then introduce the concepts of semantic fit and recontextualization to demonstrate why adaptation to host countries' moral norms may be more difficult than AMNEs anticipate. Finally, we present research on moral domains that set the context for host countries' ethical views, again making AMNEs adaptation process more arduous than most currently believe. This progression of inquiry starts at the individual level of analysis, moves to the firm, and then to cultural dimensions.

\section{Insular and Superior}

Much of the argumentation in this paper rests on an indictment of American culture- that it is overly Anglo-centric, imperialistic, and (self) perceived as superior (Henrich et al. 2010; Triandis and Gelfand, 1998). Thus, it is not without some degree of irony that our focus is exclusively on AMNEs. We do so for a variety of reasons.

First, in our area of inquiry, business ethics, a basic question is one of universalism versus relativism - to what degree ethical principles should be considered uniform across societies or unique to each different group. Philosophers generally agree that a universal approach is more sound, but relativism is still often raised as a consideration in transnational business operations (De George, 1994; Donaldson and Dunfee, 1994; Windsor, 2004). Similarly, international business strategists highlight the debate as a choice between local adaptation and global standardization. Firms tend to prefer standardizing their product offerings and business processes so they can yield efficiencies across all global operations. However, many products and processes require customization to match the unique institutional context (Brannen, 2004). This local adaptation is costly. As a result, the de facto approach is taking a Western, and often a particularly American approach, to business and business ethics. Even the extant literature on business and ethics is largely about American MNEs (De George, 1994). This effect is multiplicative when MNEs from around the world may feel the need to become isomorphic with AMNEs who are perceived as influential actors worthy of imitation. Therefore, the most powerful actors in the field not only set the rules, but also project their normative philosophies through their interactions with other economic actors including other MNEs, governments, regulatory agencies, etc. (Foucault, 1972; Martin and Swank, 2012; Vernon, 1971).

Guerra and Giner-Sorolla (2010) also note that philosophers have long debated the universal nature of morality. Universalists claim a unitary legitimate moral domain, typically concerned with protection from harm, rights, and justice (Bhatia, 2000; Miller, 2001). Although philosophers and business strategists prefer the universalist approach, either for its intellectual rigor or its efficiencies, that perspective necessarily overlooks any particularities in local cultures. Relativists, on the other hand, propose that such a rights-based code predominates primarily in Western cultures, but does not account for the entire moral domain (Chiu et al., 1997). They submit that some moral norms relate to the cultures of which they are a part (Harman, 1975; Shweder, 1990). Furthermore, the universalist thesis ignores the potential influence of religion on moral norms (Guerra and Giner-Sorolla, 2010) - as well it must, given the plethora of religious beliefs in different cultures. The current research project is clearly in the relativist camp, although it is vital to note that this argument is distinct from the moral theory of ethical relativisim.

Second, as the world's largest economy, the US has more MNEs operating throughout the world than any other country (Fortune Global 500, 2014). Third, AMNEs and their managers are unique in many ways, including being more individualistic, legalistic, and universalistic (Vogel 1992), having narrower moral domains than most other countries (Haidt, 2012), and having many sources of conflict with host countries (Calvano, 2008). Americans are often on the tails of normal distribution curves on a variety of 
cognitive and psychological measures, even among other Western cultures (Henrich et al., 2010). Selfserving biases may be much more prevalent in certain types of individualistic cultures, such as the US (Triandis and Gelfand, 1998). Fourth, the common perception is that American business ethics are "higher" than those in host countries (Peterson et al., 2010). American exceptionalism, the idea that the US is unique, notable, and remarkable, with no comparable political or civic cultures (American Enterprise Institute, 2014), connotes superiority in all dimensions - it is rarely, if ever, used to identify shortcomings in the American character.

Although most realize intellectually that such a chauvinistic approach is flawed, it still occurs regularly (De George, 1994). In AMNEs' search for ethical principles that can be applied broadly around the world, our operating assumption is that we have already identified the relevant ones.

The core idea of a common morality is that all humans - at least all morally serious humans - have a pretheoretical awareness of certain moral norms. The claim is that normal humans intuit or in some other way know that there is something wrong with things like lying or breaking promises or killing people (Veatch, 2003: 189).

All too often, those "certain moral norms" are viewed as our cultural norms with which other societies would obviously agree. However, as we will show, Americans' confidence in the applicability of their ethical principles across other cultures is ill-founded.

\section{The Individual Level - WEIRDer than We Thought}

Human nature and psychology is widely thought to be universal, but recent research has demonstrated this to be a false assumption. Subjects from WEIRD countries have been shown to think of and perceive the world differently than the vast majority of the global population. In a comprehensive review of psychological studies, these researchers found that 68 percent of all test subjects came from the United States, and fully two-thirds of them were undergraduate psychology students at American universities. Overall, a total of 96 percent came from Western countries, and 80 percent were students in psychology classes at the undergraduate level. An American student taking an undergraduate psychology course was more than four thousand times more likely to be a subject in a research project than was someone else in the world. Had the researchers acknowledged this skewed concentration of subjects, and confined their conclusions to that population, the results might not have been so misleading. However, virtually all research findings were generalized to the human population (Henrich et al., 2010).

The WEIRD research stream indicates significant differences in even basic human functioning such as visual perception, spatial cognition, analytic versus holistic reasoning, and the ways humans conceive the self. Specific to the question of ethics in different cultures, fundamental variances in fairness and cooperation in economic decision-making and in moral reasoning were noted. Even some of the most basic concepts of morality in WEIRD cultures appear to be different in other parts of the world. Kohlberg's $(1971,1976,1981)$ model of cognitive moral development posits three levels of moral reasoning. The post-conventional level, in which a person evaluates right and wrong on the basis of internally generated abstract ethical principles related to justice and individual rights, is not found in small-scale, non-Western societies (Snarey, 1985), even in highly educated non-Western populations (AlShehab, 2002; Miller, Bersoff, and Harwood, 1990). Westerners depend primarily on justice, harm, and care based principles in judging morality, while non-westerners rely on a wider range of criteria (Baek, 2002; Haidt and Graham, 2007).

WEIRD people are often at the tail end of a bell curve distribution; furthermore, Americans are often at the tail end of a bell curve distribution of WEIRD people. Culturally, AMNE managers are the outliers of the outliers, making their understanding of host countries' ethical culture even more problematic (Henrich et al., 2010). 


\section{FIGURE 1 \\ AN OUTLIER AMONG OUTLIERS}

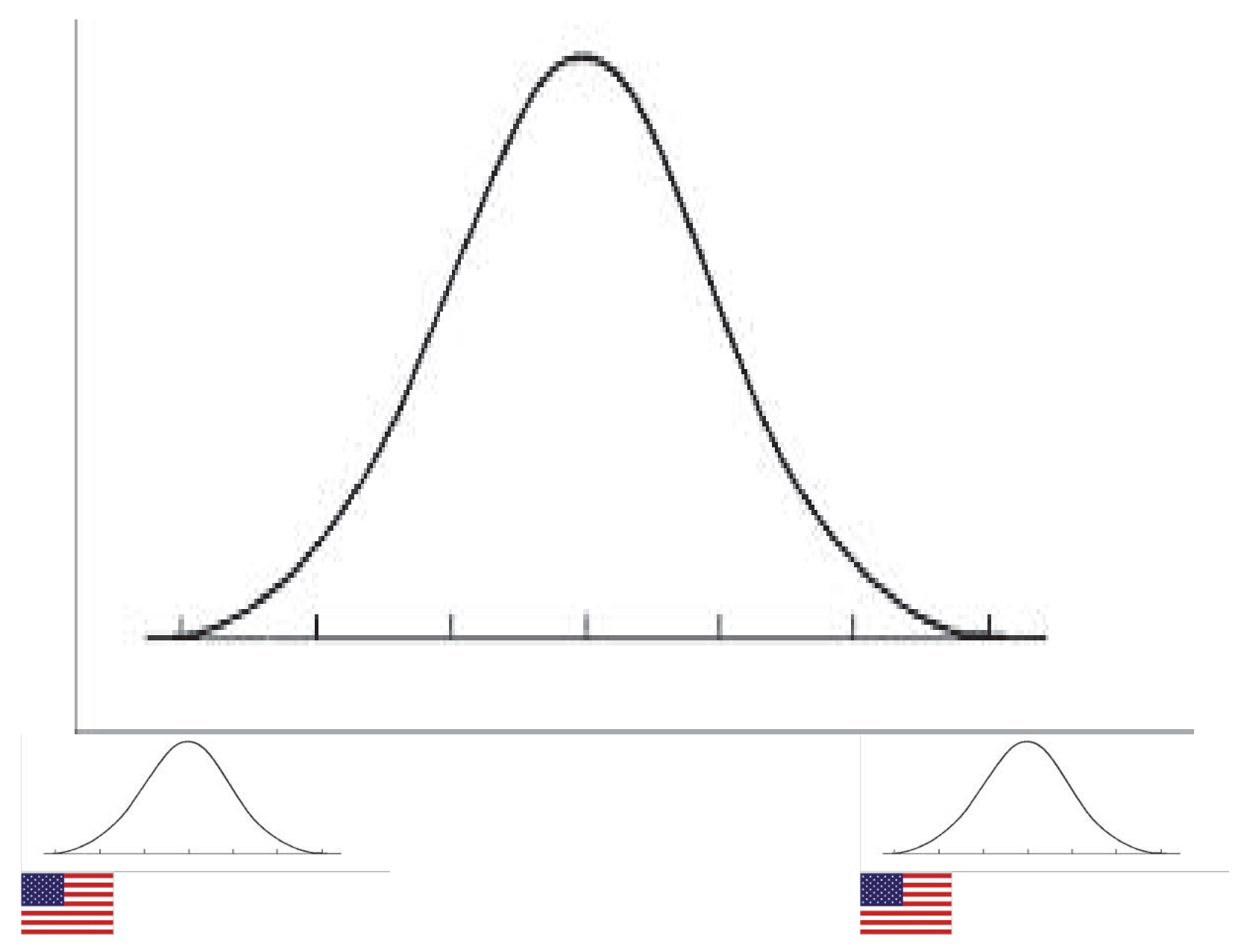

Ethics in the US is highly individualistic, rules-based, and universalistic (Haidt, 2012). In the moral realm, Americans are indoctrinated with a belief system rooted in reason and logic. All of the accepted Western moral philosophies rely on human reason as their basis, eschewing emotion as an essential element of ethical judgments. Research is demonstrating this assumption to be erroneous in the US, and perhaps even more so in other parts of the world (Guerra and Giner-Sorolla, 2010).

A person's moral perspective is largely shaped by his or her family, ethnicity, and education (Haidt, 2012). The moral domain in WEIRD cultures is unusually narrow, focusing primarily on questions of harm, rights, and justice. "Cultures differ in the degree to which one or another of the ethics and corresponding ethical 'goods' predominates in the development of social practices... For example, in the United States today we are experts on the topic of the "ethics of autonomy" [concerned primarily with individual rights and noninterference] (Shweder et al., 1997: 141-2). The ideas of moral principles based on one's role in an interdependent collective or one's connection to a sacred order have largely been sidelined in American culture.

Key to our argument that AMNE managers often fail to adequately recognize local moral and cultural standards is the fact that immersion in one ethical theme limits the conceptual resources available to understand other themes (Shweder et al., 1997). In fact, others go a step further, stating that moral matrices, the interconnected web of understanding people share about the "proper" way to think about right and wrong, blind their adherents "...to the coherence, or even existence, of other matrices" (Haidt, 
2012: 130). In other words, by holding to a particular moral system, humans are often unable to even recognize that others adhere to different moral principles. Because AMNE managers come from a decidedly WEIRD culture, their ability to recognize and adapt to host cultures is often grossly inadequate.

Anthropologists provide another perspective on the reason for these blind spots. Cultures share "basic assumptions," beliefs about how the world works and the proper ways of thinking that show little variation within the group. These basic assumptions are so deeply engrained that they become virtually invisible to those in the culture, and behavior based on any other assumptions is inconceivable. To question them, if and when they did become apparent, would be considered irrational (Schein, 1992). Basic assumptions are similar to "theories-in-use," tacit suppositions that actually guide behavior guide how group members should perceive, think, and feel (Argyris, 1976; Argyris and Schön, 1974). "Once we have developed an integrated set of such [basic] assumptions, ....we will be maximally comfortable with others who share the same set of assumptions and very uncomfortable and vulnerable in situations where different assumptions operate either because we will not understand what is going on, or, worse, misperceive and misinterpret the actions of others (Schein, 1992: 22-23). To the extent that a culture's moral matrices can be equated with its basic assumptions, one's own beliefs will be adhered to without question, while "different" moral matrices will remain unrecognized, or at best, viewed with significant skepticism.

Furthermore, American business practices are generally considered to be a "religion free" zone. Religion and spirituality are often taboo subjects in AMNEs, making cultures with an ethic related to spiritual or sacred entities even more difficult to understand (King, Bell, and Lawrence., 2009). The predominant religious backgrounds of American managers are Christianity and Judaism, which thus necessitate conscious effort and study to gain understanding of other religions. Together, these two religious traditions comprise less than one-third of the world's population (Pew Research Center, 2012). Operating in a culture where one comes from the religious majority to one in which the person is a member of the minority is likely to create many difficult issues for AMNE managers.

Finally, the moral-unity theory of business, dominant in many societies, postulates that the economic institution is viewed as an integral part of the overall society, and that it is subject to all of the same norms and moral regulations as other social institutions. In contrast, US culture generally adheres to the amoral theory of business, which views the economic institution as separate from other social institutions, such as the church, state, schools, and family. Business is largely insulated from all of the moral norms followed in the rest of society (Shepard et al., 1995). Or, as some have stated, the economic norms in the US have become the only ones that matter (Harris, 1999). Moving from a US business environment characterized by the amoral theory of business to one of moral unity will place unexpected requirements on AMNEs.

\section{The Firm Level - Adaptation Is Harder than We Thought}

It can be difficult to translate a firm's view of how the world works to another institutional context. Brannen (2004) employs qualitative analytical techniques used in semiotics to construct a model that seeks to explain the strategic fit of firms' paradigms when they are transferred across cultures. She introduces the ideas of recontextualization and semantic fit to explain how firms might reduce the "liability of foreignness" (Hymer, 1976; Kostova, 1999; Kostova and Roth, 2002) and enhance their ability to transfer the full effects of strategic assets to host country subsidiaries. Recontextualization is the process by which firm assets [myths and processes] take on new meanings in different cultural contexts (Bohanan, 1995; Brannen, 2004). Although Brannen (2004) does not specifically define semantic fit, her discussion insinuates it is how accurately signs (the associative meaning between a mental image and its underlying meaning) are understood in each new cultural context. The resulting model proposes that legitimacy (a key element in institutional theory) is conceived as having three levels: the conceptual, narrative, and discursive levels. 
The conceptual level refers to meaning at the deepest level of core values... The narrative level refers to meaning that is actualized through value-laden stories... [and] the discursive level refers to meaning that is generated figuratively by attaching values to words... (Brannen, 2004: 602).

For the purposes of this study the conceptual level is the level of deeply held cultural and religiously influenced schemata that individuals use to structure and evaluate the corporation; the narrative level is captured in the stories that locals tell to illustrate a particular point; and the discursive level is captured through definitional statements individuals use to describe their own meaning for a words such as business, globalization or ethics.

Of primary importance to the current research project, Brannen (2004: 594) notes, "...there is something about the role of the cultural context in the transnational transfer of firm assets that we are missing." She goes on to explain that such transfers are becoming even more problematic as firms seek to export increasingly complex assets and systems, including whole business models, ideologies, and moral matrices. As the complexity of transferred assets increases, the difficulty of sense-making in the host country is similarly made more complex, with substantial new opportunities for misunderstanding and error.

\section{The Cultural Level - The Big Three of Morality and World Systems Analysis}

A particularly revealing study of people in South Asia (specifically in the city of Bhubaneswar, Orissa, India) provides a lens through which scholars can understand cultural differences and apply them to various aspects of social life. The original study was aimed at the general topic of morality and health, examining how local residents understand and explain their suffering, and their moral discourse about why they suffer (Shweder et al., 1997). The authors first examined the causal ontologies of suffering — "a person or people's ideas about the 'orders of reality' responsible for suffering" (Shweder et al., 1997: 121). Previous research had provided a list of at least seven ontologies, but this project identified three primary reasons for suffering. The interpersonal mode of causal explanation externalizes blame for suffering, with the focal party being victimized by spirits, envious neighbors, domineering relatives and the like. The moral mode of explanation blames the focal agent as a consequence of personal transgressions. The third explanatory model is the bio-medical mode. Suffering is a by-product of events or circumstances beyond one's control, such as a non-smoker contracting lung cancer. The bio-medical explanation, in its pure form, relies on morally neutral causes.

The relevance of this part of Shweder et al.'s (1997) study to the current project is in the geographic distribution of explanations. The bio-medical causal ontology is prevalent in Western cultures, but is hardly ever encountered in non-Western societies (Park, 1992). Coincident with the bio-medical explanation is its lack of moral implications. The other primary causal ontologies, interpersonal and moral, are heavily imbued with moral implications, of external parties or the focal agent, respectively. From this information, the implication is that WEIRD people are less likely to attach moral implications to their suffering, and to the actions leading up to it-an AMNE manager may not recognize ethical implications in an action whereas locals may view the same action as laden with moral overtones.

The second part of Shweder et al.'s (1997) study explored the moral discourse utilized to explain people's suffering. Again, the researchers found three primary themes of moral conversation. The ethic of autonomy relies on regulatory concepts such as harm, rights, and justice. Its primary concern is protecting individuals' right to choose and to promote the exercise of individuals' free will in pursuing their personal preferences. As noted in the study, this ethic is clearly most closely associated with American society. The ethics of community depends on ideas of duty, hierarchy, and interdependence. Its aim is to protect the moral integrity of the community at large, and the roles that make it up. The ethic of divinity is based on a sacred order, tradition, sanctity, sin, and pollution. Its focus is to protect the spiritual aspects of humans and nature from degradation. How humans identify themselves (as independent agents, as one's station in life or role in a social structure, or as a spiritual entity and part of a sacred order) closely correspond to the ethics of their particular culture (Shweder et al., 1997). 
This finding bears directly on this paper's research focus. AMNEs develop in a largely secular culture with an emphasis on personal autonomy and individualism (Haidt 2012; Shweder et al., 1997). Just as the bio-medical explanation for suffering prevalent in the West brackets moral explanations, and the ethics of autonomy emphasizes individual rights and choice, so too does American business practice, through the amoral theory of business (Shepard et al., 1995). The amoral theory provides a "...complete, unified, and emotionally compelling worldview," what Haidt (2012: 125) terms a moral matrix. As noted previously, moral matrices bind people together and inhibit their ability to even recognize the existence of other matrices. Thus, an AMNE manager is unlikely to even realize that a host country employs ethics of community or divinity, much less be able to understand it and adapt to it.

A brief example will illustrate the potential for serious misunderstanding to occur because of AMNE managers' lack of knowledge of the different ethical themes. Most American managers have undoubtedly encountered the concept of karma, the idea that actions have inherent consequences. To South Asians, karma is a law of personal responsibility, with great potential for agency and personal control. It creates a feeling of inevitability that one's actions will have proportionate consequences for the self, thus providing motivation for right action. Many Westerners, on the other hand, view karma as a way for its adherents to excuse themselves from responsibility by viewing themselves as passive recipients of the forces of their past actions (Shweder et al., 1997). An AMNE manager who does not fully grasp the meaning of karma may well have a distorted view of its devotees, and miss an opportunity to motivate local workers toward a corporate goal.

Although Shweder et al.'s (1997) research was in the realm of public health policy, its lessons can and should be applied to the study of MNEs and their legitimacy in host countries. First, it highlights the major differences that cultures have in how they explain causes of suffering. Belief systems about cause/effect relationships form a central element in humans' and organizations' sense-making mechanisms, through which we interpret the world around us, provide order to information, categorize and prioritize our knowledge, and make decisions (González, Calderón, and González, 2012). Second, it shows how different ethical discourse is in various locales, and how the values underlying disparate ethical themes may manifest themselves in vastly divergent ways. This insight is crucial to our arguments that AMNEs are unique in their distance from other business ethic constructs, and in their abilities to accurately interpret, understand, and act appropriately within different ethics themes.

Another body of literature reinforces the conclusions drawn from the research on cultural diversity resulting from the Big Three of Morality. Wallerstein's $(1974,2004)$ world systems analysis provides a perspective on development that categorizes the world into core, semi-peripheral, and peripheral countries. Due largely to the rise of capitalism in the West, Wallerstein asserts that core countries (for the most part, the same as WEIRD countries) gained economic, social, and political power over other nations. Core countries became the world hegemons, creating an imperialistic colonial system. These nations focus on higher skill, capital-intensive production, and the rest of the world focuses on low-skill, laborintensive production and extraction of raw materials, thus reinforcing the core's power. Even though system operations tend to preserve the status quo, revolutions in technology and transportation make it possible for nations to change status over time. Over the past few centuries, core status has passed from the Netherlands, to the United Kingdom, and to the United States. Many speculate that the mantle may soon pass to China, as its economic power continues to expand.

America's status as a core country, and the world's lone super power undoubtedly contributes to its hubris in multinational business operations. In turn, core status is likely to contribute to moral exclusion, a condition in which some people or groups are viewed as "outside the boundary in which moral values, rules, and considerations of fairness apply" (Opotow, 1990: 1). Those who are morally excluded are seen as undeserving or expendable; thus harming them is of no consequence (Staub, 1989; Deutsch, 1990). Furthermore, some argue that moral exclusion is a psychological necessity (Volkan, 1985; Deutsch, 1990). One condition that appears to invoke the need to discriminate is a claim of superiority, based on virtually any characteristic, such as race, culture, nationality, or religion, which justifies treating the other as morally inferior (Deutsch, 1990). A quote attributed to Henry Sidgwick, professor of moral philosophy 
at Cambridge University a century ago (which, we understand, will be offensive to many of our readers), captures this concept:

We should all agree that each of us is bound to show kindness to his parents and spouse and children, and to other kinsmen in a less degree: and to those who have rendered services to him, and any others whom he may have admitted to his intimacy and called friends: and to neighbors and to fellow-countrymen more than others: and perhaps we may say to those of our own race more than to black or yellow men, and generally to human beings in proportion to their affinity to ourselves (as quoted in Singer, 2002).

These basic differences between WEIRD people and others will make deep understanding of some host countries' cultures even more opaque than most realize. Until recently, the bulk of international economic activity has been conducted among cultures that share many similarities, or has been predicated on imperialism/colonialism. Consensual global operations and open trade among starkly different cultures is a relatively new phenomenon (Eckes, 1995; Israel, 1989; Parry, 1961). However, with emerging economies such as China and India becoming primary targets of AMNE activity, our research question is increasingly vital to these firms' success.

\section{Religion and Other Factors - Harder than We Thought}

We noted above that in the US, business is regularly viewed as a "religion free" zone, and that most American firms conduct their activities under the amoral theory of business. Because religion is more intricately integrated into many foreign cultures, and is often interwoven with business practices, AMNEs are likely to be less aware of its impact on their operations in host countries.

\section{Religion and a Spikey World}

Huntington (1997), Ghemawat $(2001,2007)$ and others have argued that there are significant limits to global integration. Huntington argues that civilizational identities are remarkably durable and therefore persist in the face of forces for homogenization. Ghemawat's (2001) CAGE framework provides a four dimensional analytical tool for identifying the cultural, administrative (political), geographic and economic forces that either reflect homogeneity and integration or heterogeneity and diversity across markets. In contrast to the Flat World notion (Friedman, 2005), Ghemawat (2001) argues that a spikey world is the norm, where national differences persist - rather than the exception to the rule. Huntington also challenged the inevitability of global integration by dividing up the world into civilizations based mainly on religious and philosophical belief systems. His operationalization of civilizations was imperfect, but the core argument - that national differences are durable in the face of pressures for globalization - still holds significant merit and influence (Huntington, 1997). With the increasingly potent forces of globalization we are also witnessing the equally potent but reactionary forces of localization, fighting to protect parochial cultural interests. Religion is fundamental to these parochial interests (Buchan et al., 2009; Ghemawat, 2001, 2007; Huntington, 1997).

The relationship between religion, nationalism and modernity are critical to understanding the heterogeneous spikey-world context where AMNEs operate. This relationship is of particular importance for the present study because the modern multinational corporation (MNC) is arguably the principal driver of modernizing processes. For example, through rapid industrialization, MNCs have largely divorced themselves from the more traditional forms of production that had been the basis for civilizational accord prior to the mid-nineteenth century (El-Ansary, 2009). Furthermore, the modern disassociation of the spiritual and productive elements of work have upset the social and personal equilibrium necessary for sustainable socio-economic progress (El-Ansary, 2005; Nasr, 1982). Therefore, we will address the phenomena, the challenging theoretical perspectives, mechanisms, and implications of religion in the modern global society in which MNCs are principal protagonists. 


\section{Religion and Modernity}

Berger (1967) has described religion as a "sacred canopy" that explicates and regulates all human interaction. This shelter, however, is vulnerable to the forces of modernism that rip away the sacred canopy leaving people with only "sacred umbrellas" (Smith, 1998). Some scholars even described modernization as a process of rationalization, which left very little space for the existence of a supernatural god. For some, the scientific treatment of the natural world quickly relegated the metaphysical God to an existence in the gaps between the natural phenomena that science could explain (Weber, 1910/1978). This sentiment is echoed in the contemporary debates between the natural sciences and religion (e.g., evolution and creationism, or physics and cosmology). This religion-threatening process of scientific rationalization is also embodied in the modern science of economics where it has been asserted that, "Deities have no role in [economics]. The laws of the market are devoid of religious content. The invisible hand is not supernatural" (Emerson and Hartman, 2006: 129). Clearly this is not a reasonable or sustainable proposition for many spiritual traditions (e.g. El-Ansary, 2005).

More currently this sentiment is widely discussed in the media and common social discourse using the term postmodernism, which generally refers to the social processes of secularization, relativization, and individualization (Emerson and Hartman, 2006). In response to this tidal wave of postmodernist change that threatens tradition, societies cling to the stable, monolithic, abstract entities espoused by nationalism and religion. Kinnvall (2004) describes this relationship as "securitized subjectivity," which conveys that religion and nationalism provide the individual adherent a psychological bridge from the (mythologized) stable past through the (perceived) turbulent present and into a better future. With their reliable basis in history, religion and nationalism provide stable anchors for individuals and societies undergoing tremendous external stresses from proponents of modernization such as expanding MNC presence (Kinnvall, 2004).

\section{Religion and Nationalism}

The connection between religion and the nation/nationalism references the first notions of what modern scholars consider a nation as distinguished from an ethnie or ethnic community (Smith, 2001). To use Meinecke's designations, there is a difference between Kulturnation and Staatsnation where the former is a grouping based on a shared ancestry and ethnicity without a formal political structure, and the latter is a political union in the form of a nation-state (Smith, 2001: 19). The significance of this relationship for the study of the AMNE's ethical decisions emerges in the increasing prevalence of religion and nationalism throughout the world. AMNEs are required to transact across a multitude of religious and national boundaries that may not share their WEIRD characteristics. Such a fundamental difference in how AMNEs view host countries (as economic markets) versus how they perceive themselves (as unique regions bound together by religion, ancestry, ethnicity, and/or political beliefs) is virtually assured to cause significant friction in business operations.

Grosby (2001: 113) argues that "within the conceptual centre of each nation there is a religious element." The important relationship here is described as "religion, like nationalism, supplies existential answers to individuals' quests for security" (Kinnvall, 2004: 745). From this perspective it is easy to see that

both national and religious identity make claims to a monolithic and abstract identitythat is, to one stable identity that answers to the need for securitized subjectivity (Kinnvall, 2002). With its very long history, this monolithic "entity" becomes a stabilizing anchor in an otherwise chaotic and changing world, linking the past and the present to future action (Kinnvall, 2004: 758).

In light of the similar psychological and philosophical underpinnings of religion and nationalism it is interesting to note the radical secularism with which nationalism generally presents itself. However, Smith (2001: 22) argues 
...there are many varieties, and tensions, within the 'core doctrine' of nationalism... It is a language and culture of human association; and an important part of its widespread appeal derives from its ability to harness earlier, religious motifs, and to endow the 'nation' and the movement with those sacred qualities and liturgies previously reserved for the deity and the church.

Finally, a scholar makes the argument that "religious identity is primarily subordinated to national [identity]" (Giannakos, 2004: 52-53). This is largely due to the fact that the nation-state provides for an individual's physical security (relative security) while religion provides for an individual's metaphysical security (absolute insecurity). Therefore,

while religious institutions need to assist people in coping with absolute insecurity, they must recognize the need for relative security and cater to the identity that goes with it (Giannakos, 2004: 57).

This is important for this research because if - as Giannaakos suggests - the religious identity is of lesser importance than national identity, then nationalist narratives may emerge as the most important criteria AMNEs must consider when making ethical decisions abroad.

We have shown that ethical operation of AMNEs will require more than a superficial understanding of host countries' cultures. We will now explore current efforts to provide tools with which managers can learn to identify, understand, and take the perspective of host cultures, thus operating ethically in host cultures.

\section{CURRENT EFFORTS TO UNDERSTAND MULTINATIONAL ETHICS}

\section{Integrated Social Contracts Theory}

Perhaps the most widely recognized effort to address the issue of international business ethics is Integrated Social Contracts Theory (ISCT). Beginning some twenty years ago, two scholars published a series of papers, attempting to develop a theory that would facilitate the melding of empirical and normative research in business ethics and provide guidance to managers of MNEs seeking to conduct their business operations in an ethically justifiable manner (Donaldson and Dunfee, 1994; 1995; 1999; Donaldson, 1996).

Their central research question was, "What general principles, if any, would contractors who are aware of the strongly bounded nature of moral rationality in economic affairs choose to govern economic morality?" (Donaldson and Dunfee, 1994: 260). They sought to provide a framework for both subsequent scholarly research and for practical ways of making moral judgments in a host country, where ethical standards may be quite different than in the firm's homeland. Theirs was an attempt to present a unified normative theory incorporating empirical findings. Although presented primarily as theory development papers, the authors also specified that "ISCT is offered as a useful, pragmatic, communitarian-based theoretical framework setting forth a process for making certain normative judgments in business ethics" (Donaldson and Dunfee, 1994: 272). Our efforts in this paper make use of ISCT's practical aspects.

Key elements of their work included two levels of consent, the theoretical macrosocial contract (hypernorms) and real microsocial contracts (moral free space). Because humans have limited cognitive processing capacity, they emphasized the importance of bounded moral rationality. Its features include limited capacity to process information and a limited ability of moral theory to account for commonsense moral convictions or to provide adequate guidance for context-specific situations. They went on to stipulate that morality in economic affairs is strongly bounded due to the artificiality and plasticity of economic systems (Donaldson and Dunfee, 1994).

Donaldson (1996) presented a continuum ranging from cultural relativism (the idea that there are no universal rights or wrongs - each culture defines its own ethical standards, which are immune to critique from outsiders) to ethical imperialism, which dictates that people should always behave according to their 
home culture's ethical standards, and, in fact, should impose their native standards on foreign cultures. Rejecting both ends of the continuum as philosophically and practically indefensible, he called for a more nuanced approach that recognized core human values as minimum ethical standards for all firms doing business anywhere. These standards are also referred to as hypernorms, "principles so fundamental that, by definition, they serve to evaluate lower-order norms, reaching to the root of what is ethical for humanity" (Donaldson and Dunfee, 1999: 46). Recognizing that hypernorms, by themselves, are insufficient to provide adequate ethical guidance in all cases, individuals, firms, and cultures thus have moral free space, within which they may define moral norms according to local standards (Donaldson and Dunfee, 1994). Thus, we can relate ISCT's hypernorms to the subject of ethical universalists' argument, and moral free space to relativists' contentions.

The primary principles of ISCT include, first, agreement upon hypernorms. After that, local economic communities may specify ethical norms (principle 1), grounded in informed consent and right of exit (principle 2). Taken together, principles 1 and 2 are said to generate authentic norms. The components of moral free space must be compatible with hypernorms (principle 3), and if a conflict occurs, principle 4 stipulates that prioritization must be given to elements in accordance with the macrosocial contract (Donaldson and Dunfee, 1994).

We acknowledge the foundational status of ISCT, and commend it as an excellent starting point for further conversation. However, in our research, we have identified significant questions that remain unanswered. First, is there truly broad consensus on hypernorms? Various authors have proposed lists, but we recognize some significant differences among their constitutive elements. ${ }^{5}$ A more recent study proposes stakeholder theory (firms should take responsibility for the outcomes of their actions), comprehensive sustainability (including all efforts necessary to integrate economic activity with protection of the physical environment and improvement of social setting), and authentic compliance with the letter and spirit of legal and ethical regulations (Laczniak and Kennedy, 2011).

Our second question is at the heart of the current research project-recognition and understanding of local ethical norms (moral free space). Donaldson and Dunfee (1994) point out that two cultures may concur on a particular hypernorm, but have very different ways of carrying out specific actions to achieve compliance with it. Our research question is focused here. How can AMNEs recognize, understand, and honor local moral free space in different locales?

To their credit, these scholars explicitly noted the overriding need for MNE managers to familiarize themselves with the host country's customs and ethical norms when determining what may or may not be ethical in any foreign locale. However, because their research was published well before the advent of the WEIRD studies, they may not have realized just how difficult that proposition is.

\section{The Big Three of Morality}

As described previously, Shweder and colleagues (1997) identified three dominant themes of moral discourse, including the ethics of autonomy, community, and divinity. This framework provides an excellent starting point for identifying local moral norms, or in ISCT terminology, moral free space. However, due to the research methodology, using ethnographic techniques, open-ended interviews, free coding, and content analysis, academics and practitioners have had no standardized measures, ways to compare results, or associate findings with other constructs (Guerra and Giner-Sorolla, 2010).

A significant additional contribution to the morality literature is the introduction of horizontal and vertical dimensions of individualism and collectivism (captured in the Big Three ethics of autonomy and community, respectively). Contrary to the popular notion that individualism and collectivism are mutually exclusive dichotomies, both incorporate elements of horizontality (equality) and verticality (hierarchy). The relative emphasis placed on these dimensions is the most important attribute that distinguishes among different kinds of individualism and collectivism. For example, vertically-oriented individualistic cultures are typically geared toward competition and hedonism. Horizontally-oriented individualism places emphasis on self-reliance. Both forms of collectivist cultures are highly sociable, but the vertical

dimension also accentuates family integrity, while the horizontal element focuses on broader 
interdependence (Triandis and Gelfand, 1998). Adding these dimensions allows a more nuanced understanding of cultures, which, we argue, is desperately needed by AMNEs.

Guerra and Giner-Sorolla (2010) introduced the Community, Autonomy, and Divinity Scale (CADS) by conducting two studies, in Brazil and the United Kingdom, to develop, validate, and test a quantitative measurement of the Big Three of Morality (Shweder et al., 1997). These studies confirmed the Big Three structure. Relations among the three dimensions were tested and showed the strongest correlations between divinity and community, while community also had a positive correlation with autonomy. Divinity and autonomy were not correlated. These findings will be incorporated in our proposed model to conceptualize host countries' cultural milleaux (see Figure 3).

In addition to the ethics of autonomy, community, and divinity, these studies allowed the authors to distinguish important subscales within each category. Autonomy can be divided into emphases on positive and negative rights; community is differentiated by reliance on family or social rules; and divinity is alternatively dependent upon nature or religious rules (Guerra and Giner-Sorolla, 2010). Again, these additional distinctions can aid AMNEs' efforts to draw a more comprehensive and refined picture of foreign cultures. One significant caveat in our endorsement of this instrument is noted by the study's authors: the scales must still be evaluated for use in non-Christian cultures in terms of construct and cultural biases (Van de Vijver and Leung, 1997). This will be especially important as AMNEs participate in more emerging markets with greater cultural distance from their home.

\section{PROPOSED MODEL}

Windsor (2004) states that MNEs have four options for action in host countries: 1) adapt to the local culture, 2) adhere to a global ethics standard or exit from the host, 3) resist local laws and ethical practices the MNE deems unethical, or 4) engage with the culture to bring about desired changes in local practices. He notes, however, that all options other than adapting involve a degree of cultural imperialism, generally considered undesirable. Although we are sensitive to the hegemony of cultural imperialism, we do see all four options as ethically viable, depending on the particular circumstances encountered by an AMNE. We concur with Hsieh's (2009: 267) arguments that "MNEs have a [positive] responsibility to promote wellordered institutions in societies where they operate that are not well-ordered."

AMNEs must also grapple with legitimation strategies in each host country (Vaara et al., 2006), along with the question of what foreign businesses can and should do in their host cultures (Hsieh, 2009; Michaelson, 2010; Windsor 2004). Vaara et al. (2006) proposed five discursive strategies that social actors can use to legitimate or de-legitimate corporate activity. These are: (1) normalization, (2) authorization, (3) rationalization, (4) moralization, and (5) narrativization. Normalization is "legitimation by reference to normal or natural functioning" (797-798). This strategy is used to classify a particular phenomenon as a natural consequence of custom and tradition. Authorization is "legitimation by reference to authority" (799-800). The authority can be any individual or association that is invested with institutionalized authority. Third is rationalization, "legitimation by reference to the utility or function of specific actions or practices" (800-801). Rationalization is a strategy of cognitive cost-benefit analysis performed by the social actor. The authors also stress that a strategy of rationalization occurs within a selected moral and ideological framework. The fourth strategy, moralization, is "legitimation that refers to specific values" (801-802). In their data, it is worth noting that "an explicit moralization strategy was most visibly used for delegitimation purposes." The two most commonly used sets of values to which social actors appealed to delegitimate corporate action were nationalistic or humanistic discourses. Finally, narrativization is legitimation via narrative construction or "how telling a story provides evidence of acceptable, appropriate, or preferential behavior" (802-804). The process of narrativization was also found to include elements of other strategies such as moralization. Therefore, a story would be constructed in which the protagonists and antagonists were locked in a conflict in which only the morally virtuous would emerge victorious.

Given the theoretical orientation of this paper and the general WEIRDness of AMNEs, we believe the moralization legitimation strategy is of considerable importance. Moralization is the strategy that 
social actors employ to contest the legitimacy of AMNEs when they invoke localized conceptions of right and wrong. These local schema likely reference accepted belief systems that have been informed by religion or national culture and/or codified into government policies. This is central to Suchman's (1995) accepted definition, which claims that organizational legitimacy is a general perception that the actions of a company are proper and appropriate within the local system of norms and values. As outlined above, AMNEs are significantly handicapped by their cultural origination in their abilities to understand and respond to localized systems of norms, values and conceptions of what is desirable or proper. Therefore, if local social actors employ a moralization strategy to delegitimate the activities of an AMNE, it may go completely unnoticed or the impact of the strategy may not be fully appreciated by the American organization. Furthermore, the deeply contextualized and socially embedded nature of local moral systems makes them even more inaccessible to AMNEs, which fail to appreciate the moral implications of decisions and their consequences. As mentioned above, an AMNE manager may not recognize ethical implications in an action whereas locals may view the same action as laden with moral overtones.

Given our prior conclusion that corporations do have a positive duty to help improve local conditions, and having provided options for action in host countries, we now focus more closely on ways to identify and understand local cultures and moral matrices. Donaldson and Dunfee (1999) introduce the concept of consistent norms as an intermediary step between hypernorms and moral free space, and provide a graphic representation of ISCT, reproduced in Figure 2.

\section{FIGURE 2 DONALDSON AND DUNFEE INTEGRATED SOCIAL CONTRACTS THEORY}

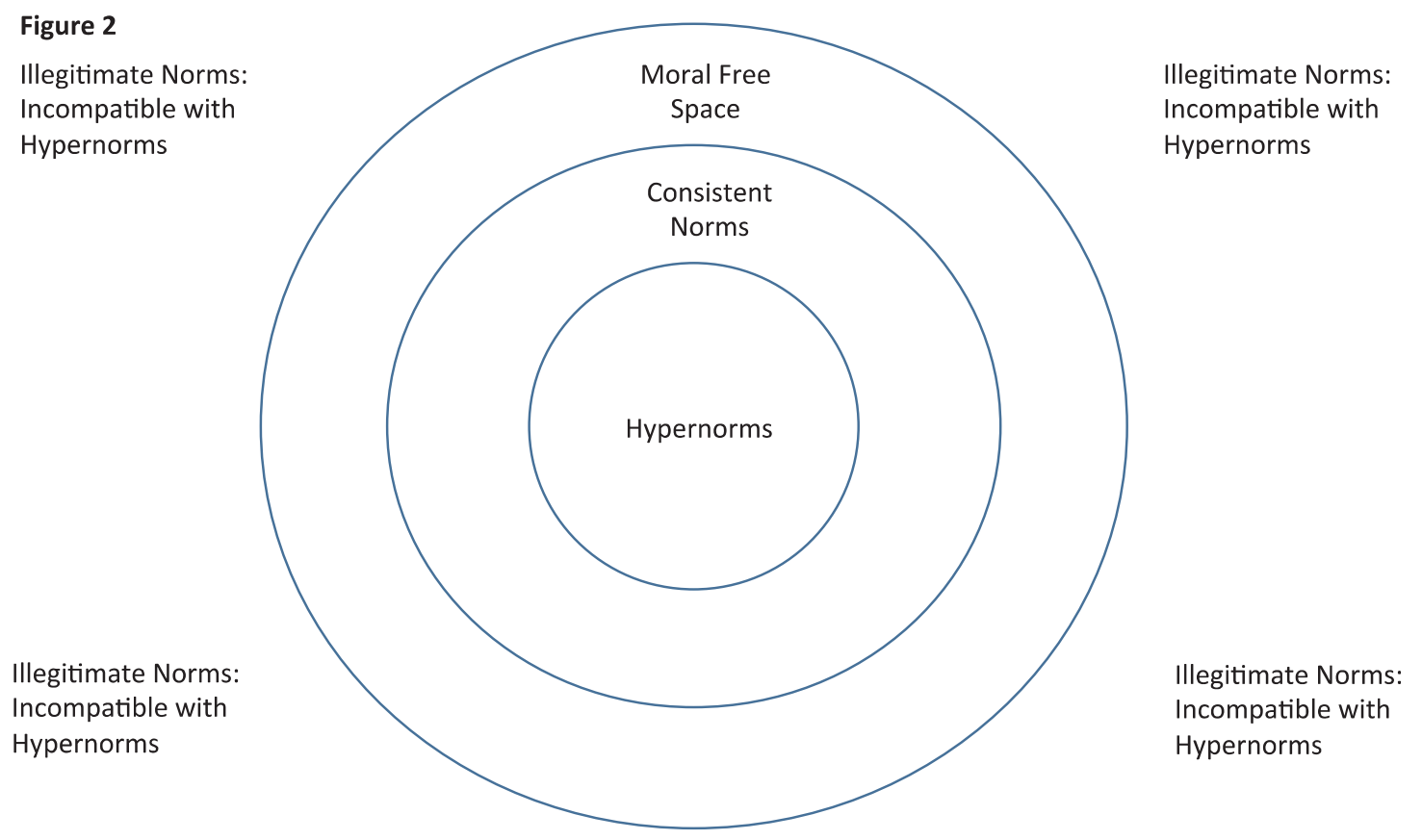

As we noted previously, hypernorms are fundamental principles that serve to evaluate lower-order norms, defining the root of what is ethical (Donaldson and Dunfee, 1994). This idea is further developed by enumerating principles that Donaldson (1996) claims constitute an overlapping consensus (Rawls, 1999): 1) people must recognize others' value as human beings, 2) individuals and communities must respect people's basic human rights, and 3) members of a community must work together to support and improve its institutions. 
The new term, consistent norms, are values that are more culturally specific than hypernorms, but also compatible with other legitimate norms (i.e., satisfies ISCT principles 1, 2, and 3). Moral free space represents local norms that may be inconsistent with other legitimate standards of behavior, and perhaps even in slight tension with hypernorms (Donaldson and Dunfee, 1999).

Overlaying the concepts of the Big Three of Morality (Shweder et al., 1997) and the CADS instrument (Guerra and Giner-Sorolla, 2010) on ISCT will allow academics and practitioners to develop a much richer, more nuanced understanding of host country cultures.

\section{FIGURE 3 \\ ENHANCED MODEL FOR UNDERSTANDING HOST COUNTRY CULTURES}

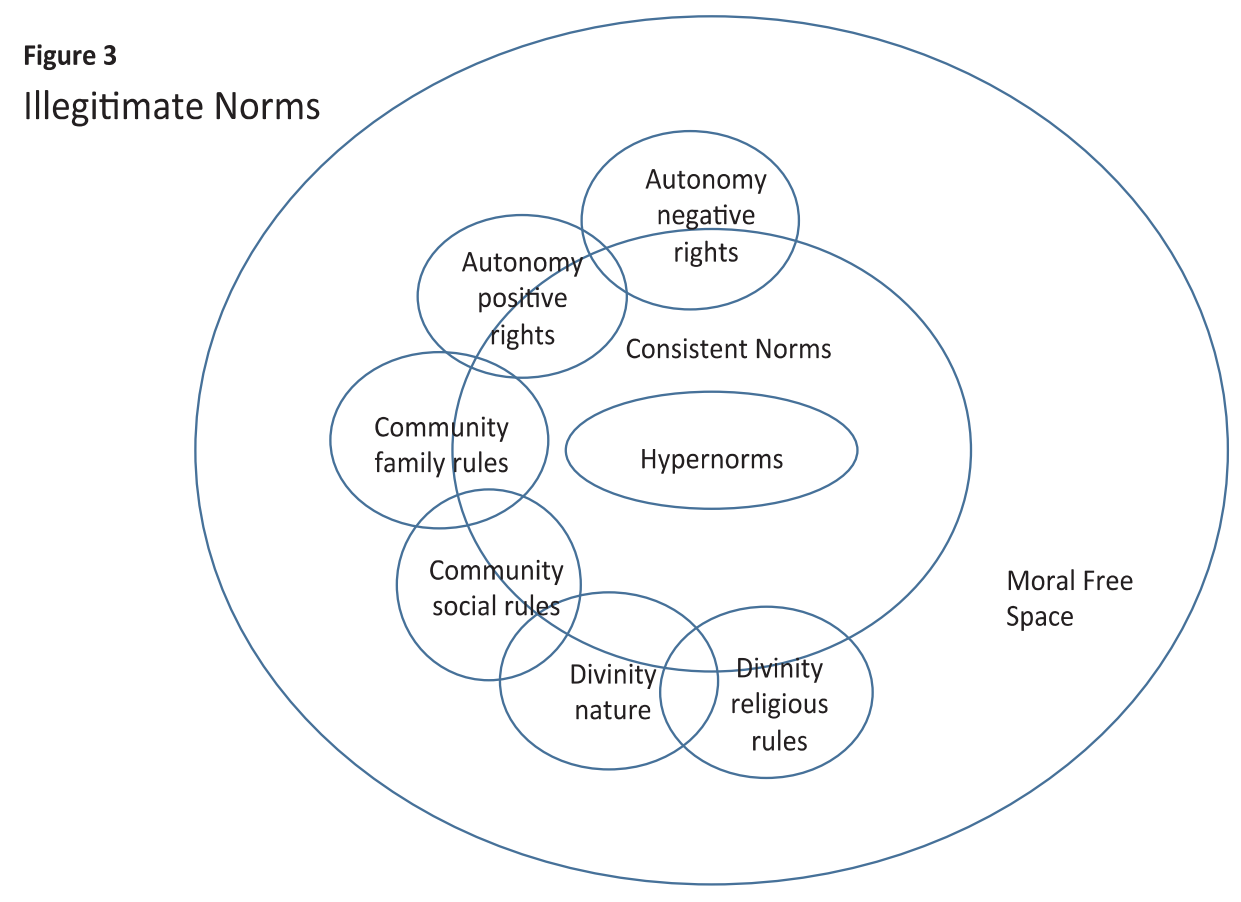

As shown in Figure 3, hypernorms remain at the center of the model, representing universally recognized moral standards. No definitive list of hypernorms now exists, or is likely to be developed (Windsor, 2004). However, others note, “... a consensus appears to be growing among scholars that such a convergence [of religious, cultural, and philosophical beliefs around certain core principles] exists (Donaldson and Dunfee, 1994: 265). Broadly speaking, most people believe in certain core moral foundations.

We include consistent norms, replicating the model shown in Figure 2. Moral free space is shown as the outer ring, but now supplemented by the six moral domains identified by the CADS (Guerra and Giner-Sorolla, 2010). These are depicted as intersecting with each other, representing the correlations among all domains except autonomy and divinity. Note that the CADS domains are conceived as being partially in the consistent norms realm and partly in moral free space. Finally, as in Figure 2, illegitimate moral norms, those incompatible with hypernorms, are noted.

By utilizing the concepts of ISCT, the Big Three of morality, and CADS, AMNEs will be able to gain a much more detailed picture of foreign cultures. This will allow them to determine where, figuratively, in the model they should attempt to place their foreign subsidiaries - or whether their theories-in-use (Argyris, 1976) will provide them a reasonable chance of success in a particular culture. 


\section{CONCLUSION}

In this paper, we sought to answer the question of how AMNEs can most effectively develop and maintain normative legitimacy in multiple host countries, given the heterogeneity of local moral matrices in which they operate. Normative legitimacy is crucial to organizations' success, because it allows acceptance in the community, opens access to resources, and provides political and social capital-in short, it is a necessary element for organizational survival.

We engaged with some of the most basic questions in business ethics, whether corporations have a positive duty to act ethically, and to aid in improving the societies in which they operate. Concluding that they do have such duties, we examined several reasons why AMNEs are arguably both the most important corporate form for which to have this discussion - with more US MNEs than any other country, from a unique culture due to its extreme WEIRDness, and a belief in American exceptionalism - and, for a variety of reasons, often very poor at recognizing and adapting to local moral matrices. We investigated many of the reasons that AMNEs do such a poor job at gaining normative legitimacy in host countries, including the WEIRD phenomenon, difficulties in exporting complex US-based business paradigms to foreign cultures, and significant differences in ethical systems that often go unrecognized or are misunderstood.

Having established that AMNEs are likely to have an especially difficult time understanding their host cultures, we then reviewed current efforts to provide assistance. Utilizing more recent research, we proposed a model that provides a more nuanced understanding of foreign culture, affording AMNEs a tool that may result in enhanced normative legitimacy.

The notion that foreign cultures are different from one's home is well recognized and noncontroversial. Virtually any AMNE manager would readily acknowledge this as an obvious truism. However, because of the WEIRD phenomenon, American hubris, the ethic of autonomy, moral exclusion, and the amoral theory of business, we posit that most AMNE managers have little idea of just how difficult it is to acquire sufficient understanding of host countries' moral matrices, thus providing a chance of gaining normative legitimacy there. This paper offers one way of discerning a more complete and refined portrait of the host culture.

\section{ENDNOTES}

1. By American multinational enterprises (AMNEs) we refer to for-profit entities that were originally formed in the United States, first did business primarily in the US, whose senior management team is populated largely with US citizens, and subsequently expanded operations to foreign markets.

2. Our assertion that AMNEs have greater difficulty establishing corporate and normative legitimacy in culturally distant cultures is sure to raise eyebrows, given the ubiquity of quintessential American brands such as McDonalds, Coca-Cola, Levis, and some NBA franchises. We acknowledge the evidence set forth in international marketing literature that certain well-recognized brand names may actually be assets of foreignness, rather than a liability (Belk, 2002; Chao, 1995). However, we also note that these situations are relatively rare; the vast majority of AMNEs do not enjoy such exalted status upon entry to a new market.

3. A related, but even larger question is whether corporations have a positive duty to improve the societies in which they operate. We address that question later in this paper.

4. Obviously, our statement about corporations' rights and duties ignores their own efforts to expand corporate rights and limit duties. At least in theory, it is still incumbent upon humans to ultimately make those policy decisions.

5. Donaldson and Dunfee (1994) provide lists of potential hypernorms offered by various scholars, most often formulated in the language of rights. See pages 265-267 to review these lists. 


\section{REFERENCES}

Al-Shehab, A. J. (2002). A cross-sectional examination of levels of moral reasoning in a sample of Kuwait University faculty members. Social Behavior and Personality, 30, 813-20.

American Enterprise Institute. (2014). Retrieved October 22, 2014, from http://www.aei.org/module/1/american-exceptionalism.

Argyris, C. (1976). Increasing leadership effectiveness. New York: Wiley-Interscience.

Argyris, C., \& Schön, D.A. (1974). Theory in practice: Increasing professional effectiveness. San Francisco: Jossey-Bass.

Aldrich, H.E., \& Fiol, C.M. (1994). Fools Rush In - The Institutional Context of Industry Creation. Academy of Management Review, 19(4), 645-670.

Baek, H. (2002). A comparative study of moral development of Korean and British children. Journal of Moral Education, 31, 373-91.

Belk, B.W. (2002). Changing consumer: Changing disciplinarity. In S. Miles. A. Anderson, and K. Meethan (eds.), The changing consumer: Markets and meanings, 145-161. London: Routledge.

Berger, P. (1967). The Sacred Canopy: Elements of a Sociological Theory of Religion. New York: Doubleday.

Bhatia, S. (2000). Can we return to the concept of duty in a culture of rights? Implications for morality and identity. Culture \& Psychology, 6, 303-316.

Bohanan, P. (1995). How culture works. New York: Free Press.

Brannen, M.Y. (2004). When Mickey loses face: Recontextualization, semantic fit, and the semiotics of foreignness. Academy of Management Review, 29(4), 593-616.

Buchan, N. R., Grimalda, G., Wilson, R., Brewer, M., Fatas, E., \& Foddy, M. (2009). Globalization and human cooperation. Proceedings of the National Academy of Sciences USA, 106(11), 4138-4142. doi: $10.1073 /$ pnas.0809522106.

Calvano, L. (2008). Multinational corporations and local communities: A critical analysis of conflict. Journal of Business Ethics, 82(4), 793-805.

Chao, P. (1995). Product country images: Impact and role in international marketing. Journal of Marketing, 59, 115-134.

Chiu, C., Dweck, C., Tong, J., \& Fu, J. (1997). Implicit theories and conceptions of morality. Journal of Personality and Social Psychology, 73, 923-940.

De George, R.T. (1994). International business ethics. Business Ethics Quarterly, 4(1), 1-9.

Deutsch, M. (1990). Psychological roots of moral exclusion. Journal of Social Issues, 46(1), 21-25.

Donaldson, T. (1996). Values in tension: Ethics away from home. Harvard Business Review, 74(5), 4862.

Donaldson, T., \& Dunfee, T.W. (1994). Toward a unified conception of business ethics: Integrative social contracts theory. Academy of Management Review, 19(2), 252-284.

Donaldson, T., \& Dunfee, T.W. (1995). Integrative social contracts theory: A communitarian conception of economic ethics. Economics and Philosophy, 11(1), 85-112.

Donaldson, T., \& Dunfee, T.W. (1999). When ethics travel: The promise and peril of global business ethics. California Management Review, 41(4), 45-63.

Dowling, J., \& Pfeffer, J. (1975). Organizational Legitimacy - Social Values and Organizational Behavior. Pacific Sociological Review, 18(1), 122-136.

Eckes, A.E. Jr. (1995). Opening America's Market: U.S. Foreign Trade Policy since 1776. Chapel Hill, NC: University of North Carolina Press.

El-Ansary, W. (2005). The Quantum Enigma and Islamic Sciences of Nature: Implications for Islamic Economic Theory. Paper presented at the 6th International Conference on Islamic Economics, Jeddah.

El-Ansary, W. (2009). Economics of Clash of Civilizations: Reexamining Religion and Violence. In Q.u. Huda (Ed.), The Crescent and Dove: Muslim Perspectives on Peace and Conflict Resolution. Washington D.C.: United States Institute of Peace. 
Emerson, M. O., \& Hartman, D. (2006). The Rise of Religious Fundamentalism. Annual Review of Sociology, 32(1), 127-144. doi: 10.1146/annurev.soc.32.061604.123141.

Fortune Global 500. (2014). Global 500 2014. Retrieved December 14, 2014, from http://fortune.com/global500/.

Foucault, M. (1972). The archeology of knowledge (A. M. S. Smith, Trans.). New York: Pantheon Books. Friedman, M. (1970). The social responsibility of business is to increase its profits. The New York Times Magazine, September 13.

Friedman, T.L. (2005). The World is Flat. New York: Farrar, Straus and Giroux.

Ghemawat, P. (2001). Distance still matters - The hard reality of global expansion. Harvard Business Review, 79(8), 137-147.

Ghemawat, P. (2007). Redefining Global Strategy: Crossing Borders in a World Where Differences Still Matter. Boston, MA: Harvard Business School Publishing Corporation.

Giannakos, S. (2004). Church and State. Harvard International Review, 25(4), 52-57.

González, J.M.H., Calderón, M.Á., \& J.L.G. González. (2012). The Alignment of Managers' Mental Models with the Balanced Scorecard Strategy Map. Total Quality Management, 23(5), 613-628.

Grosby, S. (2001). Nationality and Religion. In M. Guibernau \& J. Hutchinson (Eds.), Understanding Nationalism (pp. 97-119). Cambridge, UK: Polity Press.

Guerra, V.M., \& Giner-Sorolla, R. (2010). The community, autonomy, and divinity scale (CADS): A new tool for the cross-cultural study of morality. Journal of Cross-Cultural Psychology, 41(1), 35-50.

Haidt, J. (2012). The Righteous Mind: Why Good People are Divided by Politics and Religion. New York: Vintage Books.

Haidt, J., \& Graham, J. (2007). When morality opposes justice: Conservatives have moral intuitions that liberals may not recognize. Social Justice Research, 20, 98-116.

Hannan, M., \& Freeman, J. (1977). The population ecology of organizations. American Journal of Sociology, 83, 929-984.

Harman, G. (1975). Moral relativism defended. Philosophical Review, 84, 3-22.

Harris, B. (1999). Steal this book and get life without parole. Monroe, ME: Common Courage Press.

Hart, S.L. (2010). Capitalism at the crossraods: Next generation business strategies for a post-crisis world. Upper Saddle River, NJ: Wharton School Publishing.

Henrich, J., Heine, S., \& Norenzayan, A. (2010). The Weirdest People in the World? Behavioral and Brain Sciences, 33, 61-83.

Hsieh, N. (2009). Does global business have a responsibility to promote just institutions? Business Ethics Quarterly, 19(2), 251-273.

Huntington, S.P. (1997). The Clash of Civilizations and the Remaking of World Order. London: Simon and Schuster.

Hymer, S. (1976). International operations of national firms: A study of foreign direct investment. Boston, MA: MIT Press.

Israel, J.I. (1989). Dutch Primacy in World Trade, 1585-1740. Oxford: Clarendon Press.

King, J.E. Jr., Bell, M.P., \& Lawrence E. (2009). Religion as an Aspect of Workplace Diversity: An Examination of the US Context and a Call for International Research. Journal of Management, Spirituality and Religion, 6(1), 43-57.

Kinnvall, C. (2004). Globalization and religious nationalism: Self, identity, and the search for ontological security. Political Psychology, 25(5), 741-767.

Kohlberg, L. (1971). From is to ought: How to commit the naturalistic fallacy and get away with it in the study of moral development. In L. Mischel (Ed.), Cognitive development and epistemology, 151284. New York: Academic Press.

Kohlberg, L. (1976). Moral stages and moralization. In T. Lickona, (Ed.), Moral development and behavior: Theory, research and social issues, 31-53. New York: Holt, Rinehart and Winston.

Kohlberg, L. (1981). The philosophy of moral development. San Francisco: Harper \& Row.

Kostova, T. (1999). Transnational transfer of strategic organizational practices: A contextual perspective. Academy of Management Review, 24(2), 308-324. doi:10.2307/259084 
Kostova, T., \& Roth, K. (2002). Adoption of an organizational practice by subsidiaries of multinational corporations: Institutional and relational effects. Academy of Management Journal, 45(1), 215 233.

Kostova, T., \& Zaheer, S. (1999). Organizational legitimacy under conditions of complexity: The case of the multinational enterprise. Academy of Management Review, 24(1), 64-81.

Kotabe, M. (2002). To kill two birds with one stone: Revisiting the integration-responsiveness framework. Advances in Management, 14, 57-67.

Laczniak, G.R., \& Kennedy, A.M. (2011). Hyper norms: searching for a global code of conduct. Journal of Macromarketing, 31(3), 245-256.

Martin, C.J., \& Swank, D. (2012). The political construction of business interests: Cooperation and the evolution of the good society. New York: Cambridge University Press.

Meyer, J. W., \& Rowan, B. (1977). Institutionalized Organizations - Formal-Structure As Myth And Ceremony. American Journal of Sociology, 83(2), 340-363.

Michaelson, C. (2010). Revisiting the global business ethics question. Business Ethics Quarterly, 20(2), 237-251.

Micklethwait, J., \& Wooldridge, A. (2009). God is Back: How the Global Revival of Faith is Changing the World. New York: Penguin Press.

Miller, J. (2001). Culture and moral development. In D. Matsumoto (Ed.), The handbook of culture and psychology 151-170, New York: Oxford University Press.

Miller, J.G., Bersoff, D. M., \& Harwood, R. L. (1990). Perceptions of social responsibilities in India and the United States: Moral imperatives or personal decisions? Journal of Personality and Social Psychology, 58, 33-47.

Nasr, S.H. (1982). Review of Ethics and Economics - An Islamic Synthesis. Hamdard Islamicus, Summer, 89-92.

Oliver, C. (1991). Strategic Responses to Institutional Processes. Academy of Management Review, 16(1), 145-179. doi: 10.5465/amr.1991.4279002.

Opotow, S. (1990). Moral exclusion and injustice: An introduction. Journal of Social Issues, 46(1), 1-20.

Park, L. (1992). Crosscultural explanations of illness: Murdock revisited. Committee on Human Development, University of Chicago, Chicago, IL.

Parry, J.H. (1961). The Establishment of the European Hegemony, 1415-1715: Trade and Exploration in the Age of the Renaissance. New York: Harper \& Row.

Parsons, T. (1960). Structure and process in modern societies. Glencoe, IL: Free Press.

Peterson, R.A., Albaum, G., Merunka, D., Munuera, J.L., \& Smith, S.M. (2010). Effects of nationality, gender, and religiosity on business-related ethicality, Journal of Business Ethics, 96(4), 573-587.

Pew Research Center. (2012). The Global Religious Landscape. Retrieved May 15, 2014, from http://www.pewforum.org/2012/12/18/global-religious-landscape-exec/.

Phillips, N., Lawrence, T.B., \& Hardy, C. (2000). Interorganizational collaboration and the dynamics of institutional fields, Journal of Management Studies, 37, 23-45.

Powell, W.W. \& DiMaggio, P. (1991). The New Institutionalism in Organizational Analysis. Chicago: University of Chicago Press.

Rawls, J. (1999). A theory of justice. Cambridge, MA: Belknap Press of Harvard University Press.

Schein, E.H. (1992). Organizational culture and leadership, 2 ed. San Francisco: Jossey-Bass.

Shepard, J.M., Shepard, J., Wimbush, J.C., \& Stephens, C.U. (1995). The Place of Ethics in Business: Shifting Paradigms. Business Ethics Quarterly, 5, 577-601.

Shweder, R.A. (1990). Ethical relativism: Is there a defensible version? Ethos, 18, 205-218.

Shweder, R.A., Much, N.C., Mahapatra, M., \& Park, L. (1997). The 'Big Three' of Morality (Autonomy, Community, and Divinity), and the 'Big Three' Explanations of Suffering. In A. Brandt and P.

Rozin (Eds.), Morality and Health. New York: Routledge. 119-169.

Scott, R. (2013). Institutions and Organizations. Thousand Oaks, CA: Sage.

Singer, P. (2002). One world: The ethics of globalization. New Haven, CT: Yale University Press.

130 Journal of Management Policy and Practice Vol. 20(4) 2019 
Smith, A.D. (2001). Nations and History. In M. Guibernau \& J. Hutchinson (Eds.), Understanding Nationalism, 9-31, Cambridge, UK: Polity Press.

Smith, C. (1998). American Evangelicalism: Embattled and Thriving. Chicago: University of Chicago Press.

Snarey, J.R. (1985). The cross-cultural universality of social-moral development: A critical review of Kohlbergian research. Psychological Bulletin, 97(2), 202- 32.

Stajkovic, A.D. \& Luthans, F. (1997). Business ethics across cultures: A social cognitive model. Journal of World Business, 32(1), 17-34. doi: http://dx.doi.org/10.1016/S1090-9516(97)90023-7.

Staub, E. (1989). The roots of evil: The origins of genocide and other group violence. New York: Cambridge University Press.

Suchman, M.C. (1995). Managing Legitimacy: Strategic and Institutional Approaches. Academy of Management Review, 20(3), 571-610.

Suddaby, R. \& Greenwood, R. (2005). Rhetorical strategies of legitimacy. Administrative Science Quarterly, 50(1), 35-67.

Tracey, P. (2012). Religion and Organization: A Critical Review of Current Trends and Future Directions. Academy of Management Annals, 6, 87-134. doi: 10.1080/19416520.2012.660761.

Triandis, H.C., \& Gelfand, M.J. (1998). Converging easurement of horizontal and vertical individualism and collectivism. Journal of Personality and Social Psychology, 74, (1), 118-128

Vaara, E., \& Tienari, J. (2008). A Discursive Perspective on Legitimation Strategies in MNCs. Academy of Management Review, 33(4), 985-993.

Vaara, E., Tienari, J., \& Laurila, J. (2006). Pulp and paper fiction: On the discursive legitimation of global industrial restructuring. Organization Studies, 27(6), 789-810.

Van de Vijver, F., \& Leung, K. (1997). Methods and data analysis for cross-cultural research. London: Sage.

Veatch, R.M. (2003). Is there a common morality? Kennedy Institute of Ethics Journal, 13, (3), 189-192.

Vernon, R. (1971). Sovereignty at Bay: The Multinational Spread of US Enterprises, New York: Basic Books.

Vogel, D. (1992). The globalization of business ethics: Why American remains distinctive. California Management Review, 35(1), 35-49.

Volkan, V. (1985). The need to have enemies and allies: A developmental approach. Political Psychology, 6, 219-247.

Wallerstein, I. (1974). The Modern World-System I: Capitalist Agriculture and the Origins of the European World-Economy in the Sixteenth Century. New York: Academic Press.

Wallerstein, I. (2004). World-systems Analysis. In G. Modelski (Ed.), World System History, in Encyclopedia of Life Support Systems (EOLSS), Developed under the Auspices of the UNESCO, Eolss Publishers, Oxford, UK.

Weber, M. (1910/1978). Economy and society. Berkeley, CA: University of California Press.

Windsor, D. (2004). Business ethics in a global economy. Business Ethics Quarterly, 14(4), 729-754. 